\title{
Agôn
}

Revue des arts de la scène

Critiques | Saison 2013-2014

\section{Les Aveugles de Maurice Maeterlinck, mise en scène de Daniel Jeanneteau}

Entre fragilité et constance

\section{Caroline Châtelet}

\section{OpenEdition}

Journals

Édition électronique

URL : http://journals.openedition.org/agon/2753

DOI : 10.4000 /agon.2753

ISSN : 1961-8581

Éditeur

Association Agôn

Référence électronique

Caroline Châtelet, "Les Aveugles de Maurice Maeterlinck, mise en scène de Daniel Jeanneteau », Agôn [En ligne], Critiques, mis en ligne le 12 février 2014, consulté le 23 septembre 2020. URL : http:// journals.openedition.org/agon/2753; DOI : https://doi.org/10.4000/agon.2753

Ce document a été généré automatiquement le 23 septembre 2020.

Association Agôn et les auteurs des articles 


\section{Les Aveugles de Maurice Maeterlinck, mise en scène de Daniel Jeanneteau}

Entre fragilité et constance

Caroline Châtelet

\section{RÉFÉRENCE}

Les Aveugles - de Maurice Maeterlinck, mise en scène Daniel Jeanneteau - création au Studio-Théâtre de Vitry du 23 janvier au 3 février 2014 - http://

studiotheatre.fr

- au 104, à Paris du 8 au 16 février 2014, à 20 h30 tous les jours et les dimanches à $15 \mathrm{~h}$ www.104.fr

- à La Scène Watteau scène conventionnée de Nogent-sur-Marne les 14 et 15 mars 2014

à $20 \mathrm{~h} 30$ - http://www.scenewatteau.fr

- au Théâtre Jean-Vilar de Vitry-sur-Seine les 11 et 12 avril 2014 à $21 \mathrm{~h}$ - http://

www.theatrejeanvilar.com

1 "Mettre en scène ", ce terme cache une pluralité de pratiques et d'approches. Au risque de caricaturer, on pourrait dire que tandis que chez certains domine le souci de faire entendre un texte, pour d'autres, c'est la direction d'acteurs qui prévaut. Chez encore d'autres, comme Daniel Jeanneteau, cela relève d'une prise à bras le corps de l'espace scénique, un tropisme dû autant à sa formation qu'à sa pratique. Car s'il monte des spectacles depuis le début des années 2000, le directeur du Studio-théâtre de Vitrysur-Seine a signé de nombreuses scénographies depuis 1990. Ancien élève des écoles des Arts décoratifs et du Théâtre National de Strasbourg, c'est, d'ailleurs, par ce biais qu'il approche par deux fois l'œuvre de Maurice Maeterlinck: en 1997 avec La Mort de Tintagiles mis en scène par Claude Régy et en 2004 avec Pelléas et Mélisande monté par Alain Ollivier. Aujourd'hui, c'est en tant que metteur en scène ET scénographe que Daniel Jeanneteau aborde, avec Jean-Louis Coulloc'h à la collaboration artistique, Les Aveugles, réunissant dans un même dispositif comédiens et spectateurs. Dans cette 
pièce de 1890 du dramaturge belge, un groupe d'aveugles attend le vieux prêtre censé les ramener à leur institution. Inquiets, effrayés par les diverses manifestations de la nature environnante, ils découvrent à la fin le prêtre gisant mort à leurs côtés. Emblème du théâtre symboliste, Les Aveugles dessine des personnages en proie à leur solitude intérieure, qui prennent lentement conscience du monde qui les entoure tout en ne cessant de dire à quel point celui-ci leur échappe. Dans la mise en scène de Jeanneteau, cet éveil aux bruits du monde est collectif : pas de scène ni de salle, un seul espace envahi par un brouillard épais dans lequel les spectateurs prennent place. Installés sur des chaises éparses dont l'agencement souligne bien qu'il n'y a pas " une » direction dans laquelle regarder, les spectateurs aveugles eux aussi écoutent les personnages disséminés à leurs côtés. Rompant avec les didascalies, qui posent que le public sait dès le début que le prêtre est mort - puisqu'il le voit - pour travailler la proximité entre public et personnages, la mise en scène prend ses distances avec les interprétations habituelles. Plutôt que d'une éventuelle révélation de la misère de la condition humaine, elle installe un dispositif invitant chacun à l'écoute. Pour que l'égalité soit totale, les images sonores entendent se substituer aux images visuelles. Évoquant avec plus ou moins de force la complexité du monde alentour, la création musicale signée par Alain Mahé prend en charge les atmosphères et éléments naturels venus troubler les aveugles. Paradoxalement perdus et sans guide, ce sont pourtant eux qui mènent le public, leurs commentaires sur chaque bruit allant même jusqu'à précéder la diffusion de ceux-ci. Mais l'issue pessimiste demeure, et tandis que le brouillard se lève progressivement, accompagnant la lente prise de conscience de l'inéluctabilité de la mort, l'obscurité gagne tout le plateau. Dans ce théâtre immersif, où les artifices scéniques sont maîtrisés, ce sont les comédiens qui demeurent les plus fragiles. Parfois un peu en force, de temps à autre trop ténus, ces derniers nous rappellent que ce travail basé sur la solitude et le cheminement choral confronte à la constance d'un dispositif les aléas quotidiens d'interprétation. Et quoique réelle, cette fragilité - dont on peut considérer qu'elle disparaîtra au fil des représentations participe à sa façon du trouble de l'ensemble.

Les Aveugles

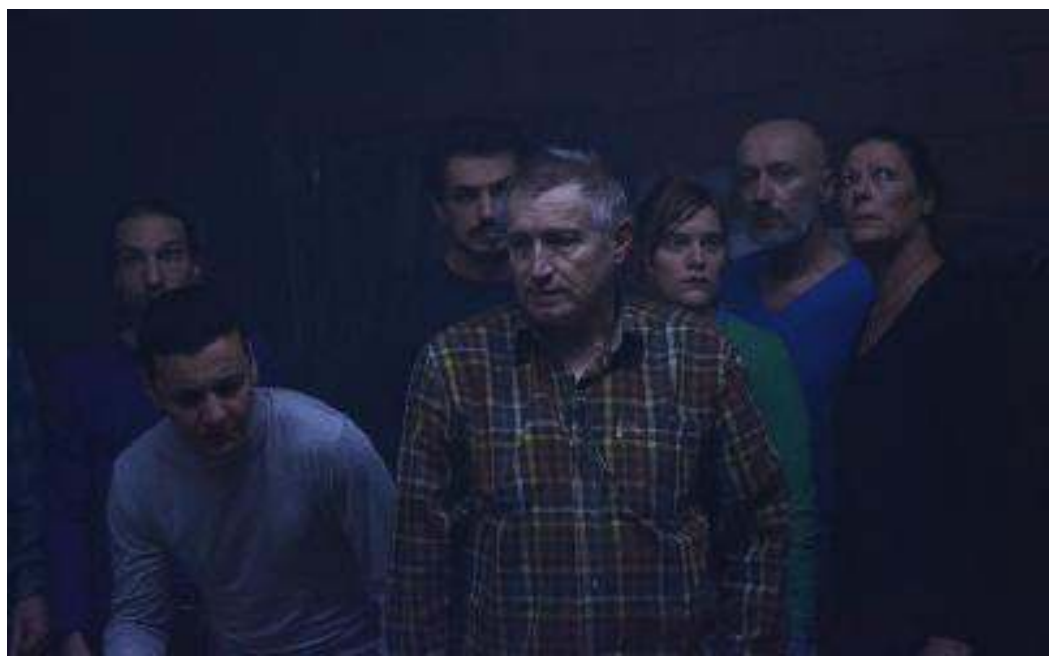

(c) Daniel Jeanneteau 